\title{
Correction to: Balancing the Environment: Computational Models as Interactive Participants in a STEM Classroom
}

\author{
Ashlyn E. Pierson ${ }^{1}$ - Corey E. Brady ${ }^{1}$ - Douglas B. Clark ${ }^{2}$
}

Published online: 21 December 2019

(C) Springer Nature B.V. 2019

\section{Correction to: Journal of Science Education and Technology https://doi.org/10.1007/s10956-019-09797-5}

The original version of this article unfortunately contained a mistake. The citation and bibliographic information of this reference is missing in the original article.

"Sengupta, P., Dickes, A., \& Farris, A.V. (2020). Voicing code in STEM: A dialogical imagination. MIT Press. Cambridge, MA (forthcoming)" and should be cited in p. 3, fourth paragraph of the section heading "Computational Models as Participants".

In this paper, we describe the work done by sixth grade students to adopt productive stances toward computational models, including stances that treat computational tools as participants in interaction and in inquiry. As described above, flexibly partnering with computational participants is becoming an essential skill within emerging STEM fields. Our data suggest that students leverage existing patterns in social interaction as resources for interacting with computational models as participants in this classroom. From a practical perspective, our data demonstrate that our students interact with their models as conversational peers. The utterances that students produce reflect the intentions and ideas of the students but are also shaped in part by the computational models (Sengupta et al, forthcoming). In combination with the probabilistic nature of the models and the students' inexperience with the environment, these participation structures position the models as co-constructors of new lines of inquiry.

The original article has been corrected.

Publisher's Note Springer Nature remains neutral with regard to jurisdictional claims in published maps and institutional affiliations.

The online version of the original article can be found at https://doi.org/ 10.1007/s10956-019-09797-5

Ashlyn E. Pierson

ashlyn.pierson@vanderbilt.edu

Corey E. Brady

corey.brady@vanderbilt.edu

Douglas B. Clark

douglas.clark@ucalgary.ca

1 Department of Teaching and Learning, Vanderbilt University, Nashville, TN, USA

2 Werklund School of Education, University of Calgary, Calgary, Canada 